\title{
Improvement of Dance Teaching Method of Preschool Education Major Based on Big Data Analysis
}

\author{
Rensisi \\ Linyi University, Yishui, Shandong, 276400
}

Keywords: Big data analysis; preschool education major; dance teaching method; improvement

\begin{abstract}
With the rapid development of the network technology, the network information presents an explosive growth, which marks the arrival of the great era. Big data analysis is valued and applied by more and more people under the background of the great era. As for the problems existing in the dance teaching of preschool education, we can also give full play to the role of big data, and put forward the feasible suggestions to the improvement of the teaching method. This article will analyze the characteristics of the current big data, as well as the problems existing in the dance teaching of preschool education major in Colleges and universities, and then put forward specific and feasible methods to improve the dance teaching methods, so as to lay a theoretical foundation for its better development.

The popularity and application of the Internet and computer make people enter into the information age. The increase in the amount of information and the speed of transmission has brought a lot of changes to our lives, which contributed to the generation of big data. Nowadays the big data has been widely applied to military, communication, finance and other industries ${ }^{[1]}$. There are many problems in present dance teaching of preschool education major in Colleges and universities, so we can use big data analysis to propose an effective way to solve the existing problems.
\end{abstract}

\section{Introduction to big data analysis}

\section{The characteristics of big data era.}

McKinsey, the world famous consulting firm, proposed the big data era, which has been widely applied to the field of communication and military, etc. In recent years because of the rapid development of the Internet industry, big data has been valued by more and more people. It was another revolution the big data raised after internet industry and cloud computing. Cloud computing provides only access to information and storage sites, and the data is the real value of the assets. Big data is often used to describe and define the mass data under the age of information explosion, as well as to name some relevant basic innovation and development.

The contents of big data analysis.

As the name suggests, big data analysis is related analysis to large-scale data. Big data itself has several characteristics, namely: multiple types, large amount of data and the value of low density. Big data contains the related contents of data analysis, data mining, data security and the data base. With the value of big data is found by more and more people, its related analysis technology has also been produced and developed.

\section{Analysis on the current situation of the dance teaching of preschool education major in Colleges and Universities}

Unreasonable curriculum arrangement in dance teaching of preschool education major.

The dance curriculum arrangement of preschool education major in most colleges and universities are learning ballet basic skills in first stage, learning classical dance in the middle stage, and then learning ethnic and folk dance, etc., and finally learning children dance ${ }^{[2]}$.

This kind of traditional teaching mode does not follow the learning principle of simple to complex and easy to difficult, and also it can not carry out a good convergence between the dances learned in early stage and children dance learned in later stage. In the process of learning not only 
the dance theory but also systematic integration study of children dance is lacked.

The number of dance teaching classes of preschool education major is not enough.

Due to the professional characteristics of pre-school education, they need to learn more basic courses, so the courses related to art skill will be correspondingly reduced. And because the time for study is not sufficient,

students can not fully understand the children dance during the studying process, which led to the children in the future dance teaching process does not attach importance to dance teaching activities, or do not have clear teaching environment, systematic teaching methods and clear teaching objectives.

\section{Dance teaching skills of preschool education major are not superb.}

The common problems existing in dance teaching of preschool education major in our country's colleges and universities are lack of teachers, low degree, shortage of professional knowledge and stagnancy of teaching and researching level. Besides, such problems still existed as the professional funds can not be effectively implemented and the related teaching supporting facilities are not perfect as well as the classroom teaching content can not be updated in time. And teaching methods are out of time, the effect is not ideal, and so on.

The irrelevance of the dance teaching theory to practice of preschool education major.

For the art teachers in colleges and universities, they rarely enter the kindergarten to experience actually and can not accurately understand the specific ideas of running schools and dance skills in current kindergarten dance teaching process, so the teachers of preschool education major failed to realize perfect cohesion between pre-service education and post-secondary improvement.

\section{The approaches to improving the dance teaching mode of preschool education major based on the big data}

\section{To enrich dance teaching content of preschool education major.}

In the whole teaching activities, teaching content is very important, which will have a direct impact on the quality of teaching results. If we want to improve the present development status in dance teaching of preschool education major such as enrich teaching content, some specific things can be done as follows,

First, dance content should be combined with the physical and psychological characteristics of students. Nowadays most college students were born in 1990s, and they are the generation who are pursuing personality. Although its tolerance ability is much better, their own characteristics still can not be ignored. For example, some dance teachers spend a lot of time training students' softness and opening, and finally caused students have psychology of fear to dance. Therefore, in the dance teaching, teachers should take students' own characteristics as the prerequisite to reduce the softness and opening training, focusing on training the body's coordination ability.

Second, reduce the proportion of folk dance appropriately. In the actual teaching process, the proportion of folk dance is relatively large, but usually a part of the folk dance is more difficult and involves more content, and therefore need more time to learn. But students' learning time in the school is limited, so they can not finish all the folk dance learning. In addition, the combination of folk dance is too single, so teachers in the teaching process should select some representative movements to teach students, so that students can learn the folk dance more reasonably and effectively.

\section{Dance teaching methods need to be used flexibly in preschool education major.}

The main purpose of applying teaching method in teaching process is to realize the teaching objectives. The most common teaching method in the current dance teaching process is still oral teaching. The whole process of teaching is done by teacher himself. The subjective position of students has not been effectively reflected ${ }^{[3]}$. With the renewal of teaching concept, many new teaching methods have been widely used, so the new teaching methods can be applied to the dance teaching of preschool education.

\section{1)The application of psychological suggestion in dance teaching}

Suggestopaedia was first proposed by a medical doctor. Its main principle is that people can 
make full use of the environment or people's own cues, unlimited potential to stimulate the brain, so that students can receive information in a pleasant atmosphere. In the actual teaching process, many students have a lack of performance, and the most important reason is their lack of confidence in the process of the performance. Therefore teachers in the process of teaching should give full play to the role of psychological suggestions. A positive expression of the teacher's eyes or a word of encouragement will have a positive implication to the students' psychology. This kind of suggestion can eliminate students' psychological tension to a certain extent, so that students can get more information to overcome the problems in the process of learning, and build up self-confidence. For example, some students will forget the movement during the dancing process, then their facial expressions will be affected even some become stiff, teachers have to do now is not to criticize but to remind the students, only when the students received the encouragement from teachers can they perform better and better.

\section{2) The application of multimedia teaching method in dance teaching}

The Internet has become an indispensable part of our life, so the dance teaching methods should also keep up with the trend of the times. Multimedia teaching facilities in schools generally include television, computer, video and other related auxiliary teaching tools. Teachers can make full use of the function of multimedia in the process of developing dance appreciation course, and show some high-quality dance to students.

For example, in the process of teaching folk dance, teachers can make use of the rich network information to collect more folk dance knowledge. For example, Chinese folk dance includes different types such as Anhui Huagudeng, Northeast Yangko dance, etc. If the information in the class is shown to the students, their knowledge will be further improved. Besides, make full use of dance video materials, this can make up for teachers in the demonstration process when they are not beautiful and not in place. The specific operation process is: teachers can use the relevant multimedia devices to show the learning content to students. Whenever the students have questions or meet difficulties, teachers can pause or replay the content and make a detailed explanation to the students.

The use of multimedia teaching can cultivate the ability of students to independently discover and solve problems, thus improve the dance teaching quality.

\section{Dance in preschool education major requires a variety of teaching forms.}

Long term use of any kind of teaching methods in the teaching process of preschool education in Colleges and universities will hinder the students' learning effect. Therefore, teachers should choose the appropriate teaching methods according to the actual situation. For example, in collective class, a teacher gives class to a whole class students, this kind of method is more convenient for management and observing the students' physical condition, so that students can learn from one another throughout the class. Another example is the group teaching methods, this method is to divide a class of students into different groups, but the number of each group should not be too much. This method is most commonly used in the current dance teaching process. The main advantages are: the teacher can observe the group members more closely, and have enough time to know each student in the group, such as student's dance foundation, imitation ability, creation ability and expression ability and so on. The students of different levels can be divided into the same group to let them help each other, or the students have a common disadvantage can be divided into one group, so that teachers can teach students in accordance with their aptitude in the teaching process.

\section{Scientific evaluation system should be established in dance teaching of preschool education major.}

Teaching evaluation is very important to measure the teaching result, and it is the key process of the whole teaching process and the guarantee of the ultimate realization of the teaching objectives, especially the evaluation of students' learning situation. The evaluation method most universities in China used before was one-time terminating evaluation, that is, during final exam process in each term, dance teachers will give score to each student, and the standard is determined by the teachers.

Children dance teaching should be the core in the dance teaching process of preschool education 
major, but the creation ability of children dance was not valued in the evaluation standard, which ignored the cultivation of students' children dance creation ability ${ }^{[4]}$. In addition, traditional terminating evaluation method should be changed in the teaching process of preschool education. All the students' information and study situation in each stage can be shown in the form of a database. We can make full use of big data mining technology, by the statistics and detailed analysis of students' ability in the whole study stage, make a judgment for the students which ability is shorted and provide a theoretical reference and theoretical guidance for the adjustment of the teaching plan. Process evaluation includes learning attitude, attendance rate, participation in dance competition, group activities, etc., so that the final evaluation results of students is also objective and true.

\section{Conclusion}

The rapid spread of the network and computer makes the information shows an explosive growth, people thus enter into the era of big data. Big data is widely applied to all aspects of people's lives, such as military, financial and other fields. It is the same for the field of education. We must also keep up with the development direction of the times. At present, there are many problems in the process of pre-school dance teaching, so we can give full play to the role of big data, analyze the present situation in detail, and provide the basis and reference for the transformation of dance teaching methods of preschool education major.

\section{References}

[1] Zhou Bingyuan. Research on dance teaching in Higher Vocational School [D]. Northeast Normal University, 2011

[2] Yue Na. Research on the practice and reform of teaching practice and reform of preschool education major [J]. Labor Security World, 2015, 29:49-51. On the Dance Teaching Reform of Preschool Education Major Based on the Current Situation of Kindergarten Dance Education [J]. Popular Literature, 2015, 14: 216-217.

[4] Wang Gongxue. On the Current Situation and Reform Strategy of. Dance Courses of Preschool Education Major in Vocational Colleges. [A]China CASWVT 2015 year outstanding achievements in Scientific Research Papers Prize (II) [C], 2015:6. 